\title{
Characterization and Performance of Minimum Quantity Lubricants in Through-Tool Drilling
}

\author{
Amla Patil, Jay Raval, Tim Bangma, Immanuel Edinbarough, Bruce Tai, David Stephenson, \\ Suleiman Obeidat and Wayne Nguyen Hung
}

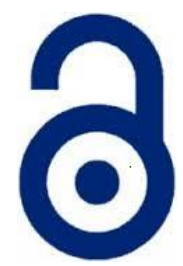

Received: 15 June 2020

Accepted: 19 August 2020

Published: 20 October 2020

Publisher: Deer Hill Publications

(c) 2020 The Author(s)

Creative Commons: CC BY 4.0

\begin{abstract}
This study characterized airborne microdroplet diameters and size distribution from two commercially available lubricants $A$ and $B$ for internal minimum quantity lubrication (MQL). The effects of air pressure, oil channel size, physical properties of lubricants on the resultant microdroplets and through-tool MQL drilling performance were studied. Airborne microdroplet diameters were highly sensitive to the coolant channel sizes and air pressure. Cluster method was used to divide microdroplets into smaller clusters for comparison. Experimental data show that the average airborne microdroplet of lubricant $B$ was larger than that of lubricant $A$ at different air pressures and channel sizes. The contact angle of lubricant $A$ was at least $10^{\circ}$ less than that of lubricant $B$ when depositing on glass or aluminium. High-speed imaging showed the tendency of more viscous lubricant B sticking to the drill tip, and higher pressure and longer time was required to atomize this viscous oil. Built-up-edges were less significant when drilling A380 aluminium with lubricant A. Due to high machinability of A380 aluminium, variation of hole diameter and hole cylindricity were minimal when drilling with different lubricants. Insignificant improvement in hole quality was observed when drilling with excessive amount of MQL lubricants or high concentration of lubricant $\mathrm{C}$ in flood coolant.
\end{abstract}

Keywords. Minimum quantity lubrication, microdroplet, contact angle, through-tool lubrication, hole quality.

\section{INTRODUCTION}

Minimum quantity lubrication (MQL) is an effective and environmentally friendly substitute to traditional flood cooling method, especially in high-aspect-ratio operation --such as gun drilling-- where cutting fluid delivery to the cutting edges is challenging. Although the topic of MQL has been investigated by many researchers, most of the published literature are for external MQL and very limited research papers were dedicated to internal or throughtool MQL. To understand how lubricant properties would affect performance of internal MQL, and possible benefits of high lubricant concentration in an aerosol mixture, this research study aimed to:

(i) Characterize and compare through-tool MQL microdroplets of two commercially available lubricants

(ii) Study microdroplet formation and flow exiting from through-tool coolant holes of a twist drill

(iii) Verify the internal MQL effectiveness with drilling experiments.

\section{LITERATURE REVIEW}

Published literature has shown the advantages of utilizing MQL in traditional machining except for grinding. This cost-effective technique reduces the cost for disposing large quantity of used and contaminated flood coolant /lubricant. It is a clean, near dry machining process as less than 2 percent of fluid adheres to the metal chips [1]. In $\mathrm{MQL}$, cutting fluid can be delivered to the cutting zone externally via one or multiple nozzles or internally via internal channels of a tool. These nozzles supply the aerosol, formed by the combination of a suitable oil and compressed air, to lubricate the cutting zone while removing heat by evaporation when micron-size oil microdroplets are propelled and adhered to the hot metal workpiece or tool surfaces. The more sophisticated internal MQL system

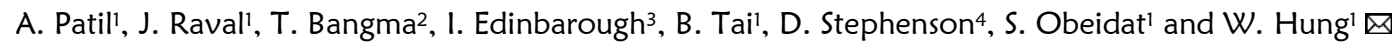

'Texas A\&M University, College Station, Texas, USA

2Unist Inc., Grand Rapids, Michigan, USA

3University of Texas, Rio Grande Valley, Brownsville, Texas, USA

4Ford Motor Company, Livonia, Michigan, USA

E-mail: hung@tamu.edu

Reference: Patil, A., Raval, J., Bangma, T., Edinbarough, I., Tai, B., Stephenson, D., Obeidat, S. and Hung, W. (2020). Characterization and Performance of Minimum Quantity Lubricants in Through-Tool Drilling. International Journal of Engineering Materials and Manufacture, 5(4), 98-115. 
supplies air-oil mixture to the cutting zone in the form of micromist through the machine spindle, tool holder, and internal channels of a cutting tool itself. The single-channel MQL system first mixes oil and air outside of a tool assembly, then pumps the mixture into the tool assembly. On the other hand, the dual-channel MQL system brings air and oil separately within parallel coaxial tubes inside a rotary union; the oil-air mixture is only formed inside the tool assembly and then flowed into the cutting tool channels to reach the tool cutting edges. Although published data for high aspect ratio drilling [2-9], or machining with external MQL [10-13] have been published, only limited published information for internal MQL was found.

Stephenson and Agapiou [14] compared the performance of one- and two-channel MQL systems. The more sophisticated two-channel system offered numerous advantages: independence of oil quantity with air flow and spindle rotation speed (up to $40,000 \mathrm{rpm}$ ), shorter reaction time (0.1-0.3 s), lower required air pressure $(400 \mathrm{kPa})$, and higher threshold for lubricant viscosity ( $100 \mathrm{~mm}^{2} / \mathrm{s}$ maximum).

Khan et al. [15] simulated through-tool MQL to study the impact of input air pressure on microdroplet sizes, and then investigated the effect of MQL on surface finish and tool wear when micromilling selective laser melted Inconel 718. The authors also included the effect of nozzle surface roughness on airborne drop sizes. Two 3D-printed ABS nozzles were used to deliver the MQL mixture: one as-printed nozzle (16.8 $\mu \mathrm{m} \mathrm{R}_{\mathrm{a}}$ surface roughness) and other acetone-polished nozzle (3.2 $\mu \mathrm{m} \mathrm{R}_{\mathrm{a}}$ surface roughness). The HAAS OM2 CNC milling system was used for milling. Coolube $2210 \mathrm{EP}$ was used as a coolant in the simulated MQL system. Milling parameters were kept constant as 13.6 $\mathrm{m} / \mathrm{min}$ speed, $1.8 \mu \mathrm{m} /$ tooth chip load, and $20 \mu \mathrm{m}$ depth of cut. The flow velocity of compressed air was measured with the Kanomax Climomaster 6501 anemometer. The authors found that at the respectively increasing air pressure of 275,415 , and $550 \mathrm{kPa}$ then the MQL drop sizes from the smooth nozzle were 11.42, 9.31, 7.60 $\mu \mathrm{m}$ while the rough nozzle broke down the MQL drop size further to $9.20,7.25$ and $4.69 \mu \mathrm{m}$. Higher air pressure of $550 \mathrm{kPa}$ generated small airborne microdroplets of about $5 \mu \mathrm{m}$ and improved surface finish of the workpiece to approximately $1 \mu \mathrm{m}$.

Kao et al. [16] studied the effect of coolant channel sizes and shapes on the mist flow in through-tool MQL drilling. Mist flow was analysed experimentally and analytically for circular and triangular coolant channels of four identical drills. Experiments were conducted on two channels with circular cross-section of 1.6 and 1.0 mm diameters; other two channels had an equilateral triangle cross-section with side lengths of 2.15 and $1.35 \mathrm{~mm}$. The air pressure and the oil flow rate were 5 bars and $45 \mathrm{~mL} / \mathrm{hr}$ respectively. A high-speed camera was used to capture the mist flow at the drill tip and an anemometer was used to measure the airspeed of the resultant micromist. The authors observed that the air flow rate of the mist varied according to the coolant channel size and shape. The airspeed was higher when exiting a larger channel. Thus, for a smaller circular channel, lubricant microdroplets were found to coalesce to form larger microdroplets. The circular channels produced higher airspeed than those of triangular channels; and the lubricant accumulated more near the drill centre point on drill with circular channels.

Raval et al. [17-18] characterized MQL micromist distribution in through-tool coolant twist drills that were fabricated with a vat photo-polymerization system. Three coolant channel shapes were included in their study: circular, triangular and the reversed triangular. A Unist dual channel MQL system with a rotary union and an atomizing chamber was used. Images from a high speed camera and data from numerical analysis were combined and compared. Frame rate was constant at $1000 \mathrm{fps}$ with a resolution of $512 \times 512$ pixels. Axial velocity component of the drill was considered negligible. Unist Coolube 2210 oil was used in the study; its flow rate was maintained at $40 \mathrm{~mL} / \mathrm{hr}$ for all the experiments. Circular coolant channels had $1.6 \mathrm{~mm}$ diameter and equilateral triangular channels had $2.15 \mathrm{~mm}$ side length, such that the cross-sectional area of the coolant channel was same in both the cases. The study concluded that the coolant channel geometry and helix angle affected the mist flow distribution. In case of $0^{\circ}$ helix angle, high flow velocity region appeared at the centre of the channel. For $30^{\circ}$ and $45^{\circ}$ helix angle, circular channel showed high velocity region away from the chisel edge, because of the centrifugal forces generated from the fluid motion in the channel. Also, high velocity regions showed low mist concentration and vice versa. Flow of aerosol mixture in multiple through-tool channels was studied by Hughey and Stephenson [19]. By modelling a channel as electrical resistance - the ratio of channel length and channel area-- the flow and response time for complete development of MQL flow can be accurately estimated.

The cutting fluid emissions produced in through-tool drilling of steel, aluminium and cast materials were investigated. Pure synthetic esters with various viscosities were used as lubricants. At a fixed drilling feed rate of 800 $\mathrm{mm} / \mathrm{min}$, the study showed that high emission of ester at cutting zone was found for fluid with low viscosity. It recommended a lubricant should have at least $10 \mathrm{~mm} / \mathrm{s}$ kinematic viscosity at $40^{\circ} \mathrm{C}$, flash point of at least $150^{\circ} \mathrm{C}$, and evaporation loss of maximum $65 \%$ at $250^{\circ} \mathrm{C}$ for low emissions of aerosol in MQL [20]. This recommendation was also cited in the German standard DIN EN ISO 2592.

Contact angle between a solid and liquid interface can directly affect the wettability of the liquid. A low contact angle between a solid and liquid interface results in liquid spreading over more area on the solid surface, improving the wettability of the liquid and its effectiveness as cutting fluid. Li et al. [21] characterized micromist using a Unist MQL system and four lubricants, viz., Coolube 2210, 2210EP, 2300HD, and 2200. These oils were tested on 316L stainless steel, titanium, and tungsten carbide to measure contact angles. Input air pressure was varied from 200 to $600 \mathrm{kPa}$, and lubricant flow rate was maintained at $1.32 \mathrm{~mL} / \mathrm{hr}$. Micromist flow was captured using particle image velocimetry (PIV) and a Hi-Sense MKII CCD camera. The distance between the nozzle and the glass plate was 130 or $150 \mathrm{~mm}$. The Olympus STM6 microscope was used for droplet size measurement and contact angle measurements. 
Airspeed of the micromist was measured using a $1 \mathrm{~mm}$ diameter needle probe of the Kanomax Climomaster 6501 anemometer. A high air pressure produced faster air speed exiting from the nozzle (up to $7000 \mathrm{~m} / \mathrm{min}$ ) and produced finer microdroplet sizes of 4-6 $\mu \mathrm{m}$ from the Coolube 2210EP. This lubricant gave the smallest contact angles of $7 \pm 5^{\circ}$ on $316 \mathrm{~L}$ stainless steel as compared to $45 \pm 5^{\circ}$ for distilled water. Tai et al. [22] studied nine commercial MQL fluids including biodegraded esters, renewable acid esters, synthetic esters, etc., and compared their thermal conductivity, wettability, lubricity, machinability and mist generation properties. The study showed that although wettability and lubricity improved for MQL fluids, heat removal property was relatively weak. Wettability was better for MQL fluids that formed small contact angles about $8^{\circ}$ to $27^{\circ}$ on polished aluminium and tungsten carbide. However, the waterbased coolant Trimsol with $5 \%$ concentration, showed contact angle of about $35^{\circ}$ on the same polished solids.

The A380 aluminium is die cast to make engine blocks in automobile industry. Deep hole drilling at fast production rate using internal MQL is required. This study compares two commercially available lubricants and finds optimal MQL parameters for drilling this aluminium alloy.

\section{EXPERIMENTS}

Die cast A380 aluminium plates ( $420 \times 175 \times 24 \mathrm{~mm}$ thick) were commercially obtained. Typical A380 aluminium alloy (wt\% 7.5-9.5 Si, 3-4 Cu, 3.0 Zn, 1.3 Fe, 0.5 Mn, and balance Al) has $324 \mathrm{MPa}$ ultimate tensile strength, 159 MPa yield strength, 3.5\% elongation, and $80 \mathrm{HB}$ hardness [23]. The following section describes setups and procedures to measure contact angles, characterize the resulting microdroplets, observe the forming of microdroplets out of the drill lubricant channels, drill the aluminium plate, and finally assess the drilled hole quality.

\subsection{Contact Angle Measurement}

Sessile-drop technique was utilized to measure contact angles of both lubricants. The flat surfaces of a glass panel or a polished A380 cast aluminium block were cleaned with acetone before each experiment. Microdroplets, $0.1 \mu \mathrm{L}$ volume that dispensed from the Socorex micropipette, were carefully deposited on the horizontal solid surface. The projected images of at least ten microdroplets were measured using the Olympus STM6 measuring microscope with $0.1 \mu \mathrm{m}$ resolution. Coordinates of multiple points on a microdroplet perimeter were recorded for calculating the average microdroplet diameters. Care was practiced avoiding microdroplets near a surface defect such as microscratches or pore on the cast aluminium block.

\subsection{Microdroplet Characterization}

The Unist system and setup, simulated a dual channel MQL system, generated micromist microdroplets into a stationary drill with dual coolant channels (Fig. 1). Controlled pressured air, flowing through the Unist system via a coaxial tube, mixed with the liquid lubricant and delivered the aerosol mixture at the drill shank. The mixture then flowed inside the dual channel drill following the tool helix angle and emitted out from two circular holes at the drill tip. Details of the drills and lubricants are listed in Tables 1-2. The Unist system pumped 40 strokes/min that delivered $0.016 \mathrm{~mL} /$ stroke $(38.4 \mathrm{~mL} / \mathrm{hr})$. The distance between drill tip and the horizontal glass panel was $355 \mathrm{~mm}$ for best distribution and collection of the microdroplets. The stationary drills and all experiments were conducted in still air, assuming (i) insignificant effect of drill rotation, and (ii) negligible evaporation of airborne microdroplets. The input air pressure was at three levels to study the resulting microdroplets and flow pattern: $413 \mathrm{kPa}$ (4.13 bar, 60 psi), 551 $\mathrm{kPa}(5.51 \mathrm{bar}, 80 \mathrm{psi})$, and $689 \mathrm{kPa}$ (6.89 bar, $100 \mathrm{psi})$. Air flow rates were fixed at 0.566 and $1.7 \mathrm{~m}^{3} / \mathrm{hr}$ for the 4 and $8-\mathrm{mm}$ drills respectively.
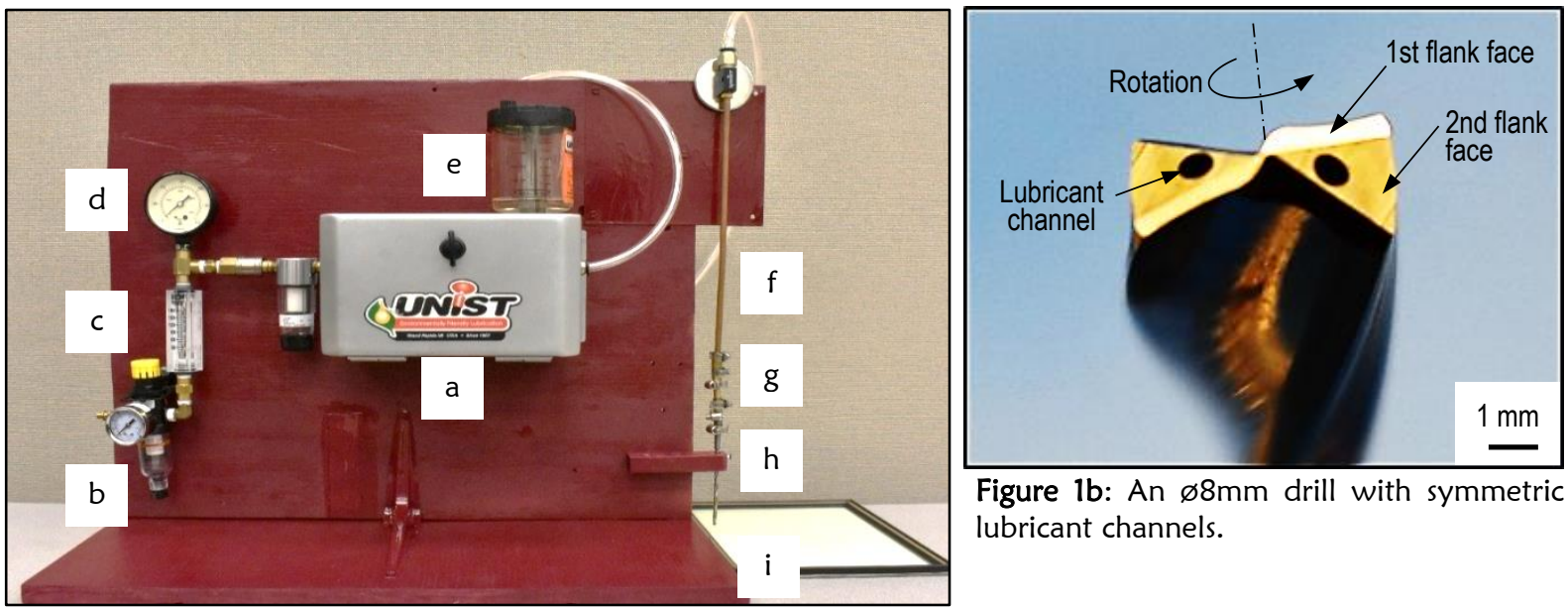

Figure 1b: An $\varnothing 8 \mathrm{~mm}$ drill with symmetric lubricant channels.

Figure 1a: Experimental setup for microdroplet characterization.

Where, a: Unist Coolubricator system, b: air filter/regulator, c: air flow meter, d: pressure gage, e: lubricant reservoir, f: copper tube, g: pressurized aerosol chamber, h: drill with dual internal coolant channels, and i: glass panel. 
Table 1. Specifications of tested drills

\begin{tabular}{lcc}
\hline Specifications & Small drill [24] & Large drill [25] \\
\hline Measured drill diameter $(\mathrm{mm})$ & 3.889 & 8.0 (nominal) \\
Drill diameter for lubricant C (mm) & $\mathrm{n} / \mathrm{a}$ & $7.9950 \pm 0.0007$ \\
Drill diameter for lubricant A (mm) & $\mathrm{n} / \mathrm{a}$ & $7.9958 \pm 0.0008$ \\
Drill diameter for lubricant B (mm) & $\mathrm{n} / \mathrm{a}$ & $7.9952 \pm 0.0004$ \\
Number of flutes & 2 & 2 \\
Coolant channel diameter (mm) & 0.7 & 1.0 \\
Distance between coolant channels (mm) & 2.4 & 3.8 \\
Helix angle $\left({ }^{\circ}\right)$ & 20 & 15 \\
Included /point angle $\left({ }^{\circ}\right)$ & 140 & 135 \\
\hline
\end{tabular}

Table 2. Tested oil-based lubricants

\begin{tabular}{lcc}
\hline Properties & Lubricant A & Lubricant B \\
\hline Kinematic viscosity at $40^{\circ} \mathrm{C}\left(\mathrm{mm}^{2} / \mathrm{s}\right)$ & 14.5 & 28 \\
Flashpoint $\left({ }^{\circ} \mathrm{C}\right)$ & 93 & 180 \\
Density $(\mathrm{kg} / \mathrm{L})$ & $0.82-0.92$ at $60^{\circ} \mathrm{C}$ & 0.838 at $20^{\circ} \mathrm{C}$ \\
Thermal conductivity at $40^{\circ} \mathrm{C}\left(\mathrm{W} / \mathrm{m}^{\circ} \mathrm{K}\right)$ & Not available & 0.1593 \\
\hline
\end{tabular}

A glass plate $(220 \times 280 \times 3 \mathrm{~mm}$ thick) was divided into 8 different $25 \times 25 \mathrm{~mm}$ zones, each at a unique radial distance and polar angle from the drill tip projection position (Table 3). The glass plate was cleaned with ammonia-based glass cleaner and acetone before each experiment. After verifying the steady state of MQL aerosol flow with visual oil wetting on a piece of paper, a diaphragm was opened for 2 seconds to allow optimal deposition of microdroplets on the glass plate below. The plate was immediately positioned under the Olympus STM6 measuring microscope for capturing closed-up images of the microdroplets. Five random pictures were taken within each zone for analysis. The built-in light of the microscope had minimum intensity in still air to minimize vaporization of oil microdroplets during this operation. The captured microdroplet images were enhanced and statistically analysed using Adobe Photoshop and ImageJ software. Each picture was calibrated by comparing number of pixels and a known distance. The areas of projected microdroplets and known contact angle were used to calculate the airborne microdroplet sizes. The Kmeans clustering method was used to characterize the microdroplets.

Before switching to a new oil, the reservoir and connecting hose of MQL system were first rinsed with warm water and liquid soap, and then operated with dry air to flush out the water. After filling the reservoir with a new oil, the system was operated for at least 15 minutes to flush out any remained soapy water.

Table 3. Different zones for microdroplet collection

\begin{tabular}{lrrrrrrrr}
\hline Zone \# & 1 & 2 & 3 & 4 & 5 & 6 & 7 & 8 \\
\hline Radial distance (mm from drill tip projection) & 0 & 39 & 51 & 40 & 61 & 61 & 93 & 93 \\
Radial angle $\left(^{\circ}\right)$ & 0 & 220 & 270 & 320 & 25 & 155 & 235 & 305 \\
\hline
\end{tabular}

\subsection{Microdroplet Formation and Flow}

Macro images of microdroplets and flow at the drill tip were captured for both lubricants. Showing in Fig. 2, a drill was positioned between the high-speed camera Photron FASTCAM SA5 and the Halogen Work Light E216569. Three tandem extension tubes of 12,20, and $50 \mathrm{~mm}$ were attached in front of the camera lens to reduce the effective focus length. A white paper sheet was placed on the lamp and optimally placed at a long distance from the drill for best background illumination while reducing heat to the aerosol. The Unist system pumped at 40 strokes/min and delivered $0.016 \mathrm{~mL} /$ stroke. After the MQL reaching its steady state, a diaphragm was unblocked, and the camera was kept on for 0.47 second to capture 42,000 frames/s at $1 \mu$ s shutter speed and $512 \times 320$ pixels/frame. The Photron FASTCAM viewer version 4.0 was used to analyse subsequent images.

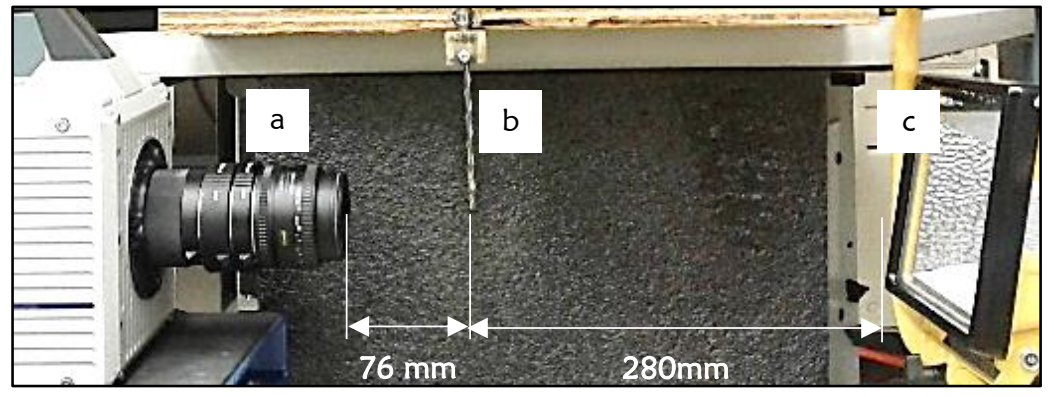

Figure 2. Setup for viewing microdroplet formation and flow. Where, a: Photron video camera with extension tubes, b: drill, and c: light source. The distances were selected for optimal focus and lighting. 


\subsection{Drilling}

Production rate drilling was implemented to drill the die cast $A 380$ aluminium plate with $8 \mathrm{~mm}$ drills. Each new drill was used with a different coolant while keeping drilling parameters constant ${ }^{1}$. The studies were carried out at two different locations where internal MQL and lubricants were available. Drilling with flood coolant and dry conditions were also experimented for comparison. Table 4 details the drilling study and process parameters.

Two-level factorial experiments, with two replicates, were used to study the effect of air pressure $(413,620 \mathrm{kPa})$ and MQL oil quantity $(40,60 \mathrm{~mL} / \mathrm{hr})$ on the hole quality. The experiments were then repeated at the same air pressure range but at much higher MQL oil quantity $(100,400 \mathrm{~mL} / \mathrm{hr})$. The same drill was used to drill five consecutive holes at each condition, and a total of 80 holes were drilled for each lubricant with machines at locations $A$ and $B$. At location $C$ a new drill was utilized for drilling with flood coolant for a total of 20 holes, and the same drill was used for the final drilling at dry condition.

Table 4. Drilling experiments

\begin{tabular}{llll}
\hline & Location A & Location B & Location C \\
\hline CNC drilling machine & Haas VF2 & GROB 515 5-axis (B/A) & FANUC Robodrill, $\alpha$ - \\
& & & D21LiB5 \\
Spindle speed capacity (rpm) & 15,000 & 16,000 & 10,000 \\
Cutting fluid type & MQL & MQL & Flood, water soluble \\
Cutting fluid & Lubricant A & Lubricant B & Coolant C \\
Cutting speed (m/min) & 250 & 250 & 250 \\
Spindle speed (rpm) & 9,950 & 9,950 & 9,950 \\
Chip load (mm/flute) & 0.20 & 0.20 & 0.20 \\
Feed rate (mm/min) & 3,980 & 3,980 & 3,980 \\
MQL oil quantity (mL/hr) & $40,60,100,400$ & $40,60,100,400$ & $\mathrm{n} / \mathrm{a}$ \\
Flood coolant quantity (L/hr) & $\mathrm{n} / \mathrm{a}$ & $\mathrm{n} / \mathrm{a}$ & 340,5678 \\
Air pressure (kPa (psi)) & $413,620(60,90)$ & $413,620(60,90)$ & $\mathrm{n} / \mathrm{a}$ \\
Flood coolant concentration (\%) & $\mathrm{n} / \mathrm{a}$ & $\mathrm{n} / \mathrm{a}$ & 5,10 \\
Flood coolant pressure (kPa (psi)) & $\mathrm{n} / \mathrm{a}$ & $\mathrm{n} / \mathrm{a}$ & $76,83(11,12)$ \\
\hline
\end{tabular}

\subsection{Metrology}

After machining, the profiles of drill cutting edges were scanned with the Alicona optical 3D profiler for possible tool damage during drilling.

The machined plate and all holes were cleaned with alcohol and blow-dried with compressed air before measuring. For each hole, its diameter and cylindricity were measured with the Mitutoyo Strato-Apex 7106 coordinate measuring machine and programmed using the accompanying software (MCOSMOS-3 version 3.2 R6 Edition 6). After setting the coordinate system on the plate with origin at one of the plate corners, five points were probed at hole depth level of 3, 9, and $15 \mathrm{~mm}$ from the top (drill entrance position) for hole diameters and hole cylindricity (Fig. 3).

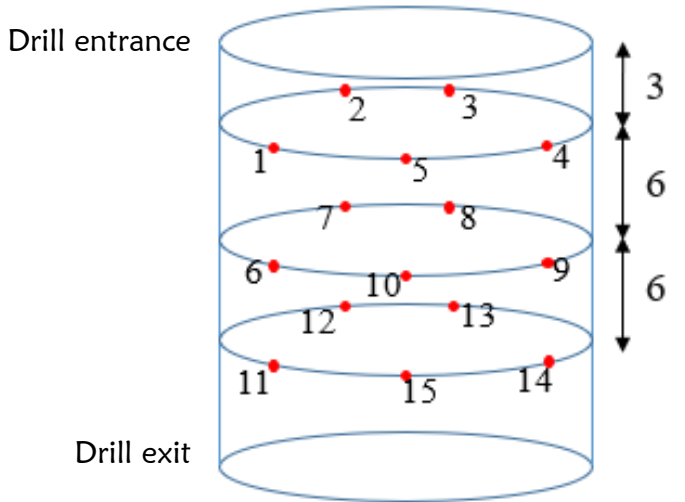

Figure 3. Schematic of cylindricity measurement for each drilled hole.

The typical numbers (1-5) represent probed points on a circle $3 \mathrm{~mm}$ below the drilled hole entrance. Unit: $\mathrm{mm}$

\footnotetext{
1 Machinery Handbook, 29 ed., p 1043.
} 


\section{RESULTS AND DISCUSSION 4.1 Contact Angles}

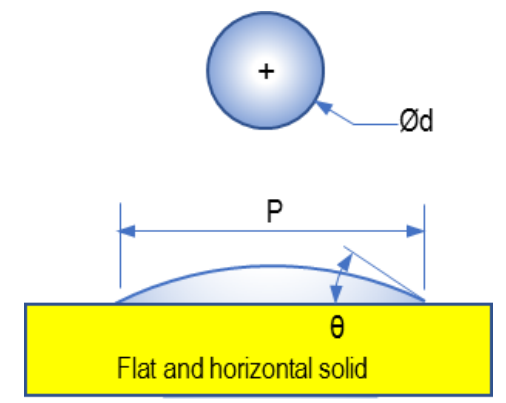

Figure 4. Airborne microdroplet and a sessile microdroplet on a flat solid.

In the sessile drop technique, a small microdroplet would form a spherical shape in air or on a flat solid surface to minimize its surface energy (Fig. 4). It can be shown that the drop volume $V$ of a sessile drop, its projection size $P$ and the contact angle $\vartheta$ are related by [26]:

$$
\frac{P}{V^{1 / 3}}=\left[\left(\frac{24}{\pi}\right)\left(\frac{\left(1-\cos ^{2} \theta\right)^{3 / 2}}{2-3 \cos \theta+\cos ^{3} \theta}\right)\right]^{1 / 3}
$$

Table 5. Resulted contact angles

\begin{tabular}{|c|c|c|c|c|}
\hline \multirow{2}{*}{$\begin{array}{l}\text { Solid substrate } \\
\text { Lubricant }\end{array}$} & \multicolumn{2}{|c|}{ Glass } & \multicolumn{2}{|c|}{ Polished A380 } \\
\hline & A & B & A & B \\
\hline \multirow{15}{*}{$\begin{array}{l}\text { Projected diameter (mm) } \\
\text { resulted from } 0.1 \mu \mathrm{L} \text { oil drops }\end{array}$} & 2.188 & 1.515 & 1.557 & 1.218 \\
\hline & 2.288 & 1.560 & 1.394 & 1.429 \\
\hline & 2.249 & 1.559 & 1.266 & 1.100 \\
\hline & 2.201 & 1.317 & 1.426 & 1.239 \\
\hline & 2.150 & 1.326 & 1.318 & 1.072 \\
\hline & 2.130 & 1.230 & 1.349 & 1.237 \\
\hline & 2.143 & 1.248 & 1.353 & 1.100 \\
\hline & 2.089 & 1.453 & 1.306 & 1.407 \\
\hline & 2.108 & 1.435 & 1.323 & 1.131 \\
\hline & 2.126 & 1.506 & 1.336 & 1.176 \\
\hline & 2.408 & 1.508 & 1.047 & 1.253 \\
\hline & 2.398 & 1.528 & 1.863 & 1.133 \\
\hline & 2.126 & 1.507 & 1.414 & 1.094 \\
\hline & 2.116 & 1.190 & 1.552 & 1.256 \\
\hline & 2.133 & 1.223 & 1.851 & 1.119 \\
\hline Average diameter (mm) & $2.190 \pm 0.101$ & $1.407 \pm 0.135$ & $1.424 \pm 0.212$ & $1.198 \pm 0.110$ \\
\hline Contact angle $\left(^{\circ}\right)$ & $5.60 \pm 0.70$ & $21.49 \pm 6.31$ & $21.81 \pm 8.63$ & $33.16 \pm 7.27$ \\
\hline
\end{tabular}

Since glass and A380 aluminium have different surface energies, it is expected and confirmed that the respective contact angles would be different on each material. Table 5 shows that the lubricant $A$ forms smaller contact angles than those of lubricant $B$ on both glass $\left(6^{\circ}\right.$ versus $\left.21^{\circ}\right)$ and aluminium $\left(22^{\circ}\right.$ versus $\left.33^{\circ}\right)$. This implies that the former lubricant can (i) cover and wet a larger area for more efficient heat transfer and (ii) self-spread by capillary action to bring lubricant to a hard-to-reach area such as tool/chip interface. The better wetting of lubricant $A$ was due to its lower surface energy and lower viscosity [14].

\subsection{Airborne Drop Sizes}

A raw image of microdroplets deposited on a glass plate was enhanced using Photoshop and then converted to binary format using ImageJ software (Fig. 5). The area and projected size of each microdroplet can then be calculated and tabulated. Assuming no evaporation of the lubricant, a spherical airborne microdroplet with volume $V_{a}$ and diameter $d$ would deposit on the glass plate and form a tiny sessile microdroplet with the same contact angle (Fig. 4).

\section{Define}

$P$. Projected size of a sessile drop from micropipette

$V$ : Volume of a sessile drop, set with the micropipette

$P_{a}$ : Projected size of an MQL sessile microdroplet

$V_{a}$ : Volume of an airborne MQL microdroplet

d: Diameter of an airborne MQL microdroplet 
Since the ratio $P /(V)^{1 / 3}$ is a function of contact angle only, equation (1) yields:

$$
\frac{P^{3}}{V}=\frac{P_{a}{ }^{3}}{V_{a}}=\left(\frac{24}{\pi}\right)\left(\frac{\left(1-\cos ^{2} \theta\right)^{3 / 2}}{2-3 \cos \theta+\cos ^{3} \theta}\right)=\text { constant }
$$

Since the volume of a spherical airborne microdroplet is the same with microdroplet volume deposited on the glass:

$$
V_{a}=\frac{\pi}{6} d^{3}=V\left(\frac{P_{a}}{P}\right)^{3}
$$

By combining equations (2) and (3), the airborne microdroplet diameter $d$ can then be calculated as:

$$
d=\frac{P_{a}}{P}\left(\frac{6 V}{\pi}\right)^{1 / 3}
$$
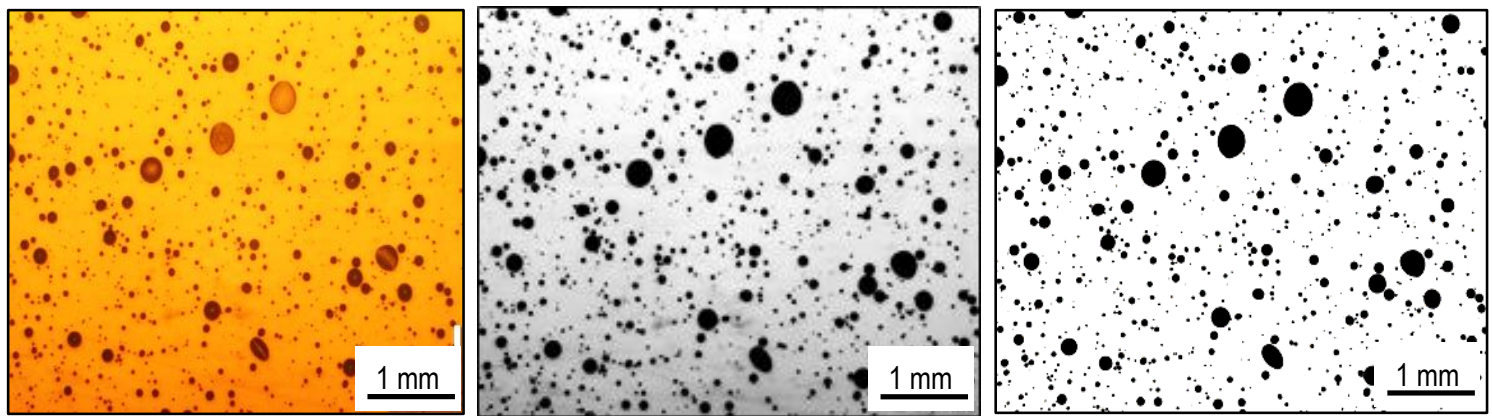

(a) Typical image of microdroplets at location $0 \mathrm{~mm}$ radial distance from the drill projection.

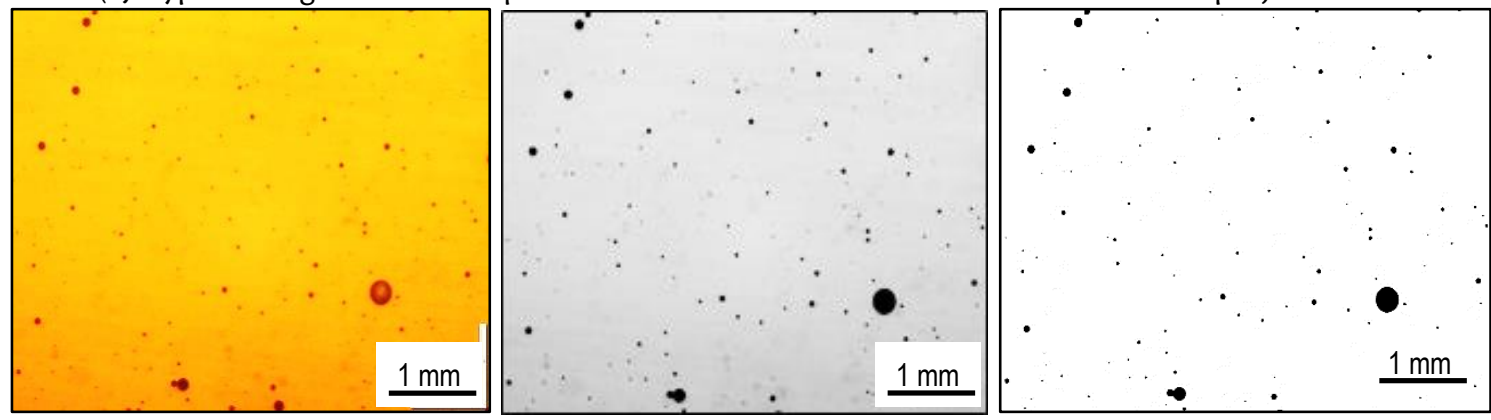

(b) Typical image of microdroplets at location $93.4 \mathrm{~mm}$ radial distance from the drill projection.

Figure 5. Images of lubricant B microdroplets on glass after spraying at $413 \mathrm{kPa}$.

Left to right: raw images, after enhanced with Photoshop, and after conversion to binary format with ImageJ.

The distributions of airborne microdroplets due to different air pressures and drill diameters are presented in Figs. 67. For MQL drop size analysis, the main difference in drill size is the diameters of lubricant hole channels. The channel hole diameter on the larger drill is $1.0 \mathrm{~mm}$ while that for the smaller drill is $0.7 \mathrm{~mm}$ (Table 1). The summary of all means and standard deviation of microdroplets from both Figs. 6-7 is shown in Fig. 8. It is found that:

- The averaged drop size decreases with increase in air pressure. A higher pressure breaks down a lubricant drop into smaller drops as also experimentally shown in other studies [15, 21].

- The larger drill with large coolant hole channel produces smaller drop size. The average air speed, exiting out of the larger lubricant hole, is about $300 \mathrm{~m} / \mathrm{s}$ while that from a smaller hole is approximately $200 \mathrm{~m} / \mathrm{s}$ (Table 6). These air speed magnitudes in this study are very close to experimental data from different coolant hole channels and seem independent of the tested air pressure in the range 4.3-10 bars (430-1000 kPa) [27]. A highspeed air might flow turbulently in a helical channel and further break down large lubricant drops. Similar conclusion was also obtained by others $[15-17,20,28]$.

- The smallest average airborne drop sizes (about $8 \mu \mathrm{m}$ ) can be produced with the $8 \mathrm{~mm}$ drill using lubricant $A$ at $551 \mathrm{kPa}$ pressure. These conditions also provide the most uniform drop size (minimum standard deviation).

Table 6. Air speed calculation

\begin{tabular}{cccccc}
\hline $\begin{array}{c}\text { Drill size } \\
(\mathrm{mm})\end{array}$ & $\begin{array}{c}\text { Coolant hole } \\
(\mathrm{mm})\end{array}$ & $\begin{array}{c}\text { Hole area } \\
\left(\mathrm{m}^{2}\right)\end{array}$ & $\begin{array}{c}\text { Total air flow } \\
\left(\mathrm{m}^{3} / \mathrm{hr}\right)\end{array}$ & $\begin{array}{c}\text { Air speed } \\
(\mathrm{m} / \mathrm{min})\end{array}$ & $\begin{array}{c}\text { Air speed } \\
(\mathrm{m} / \mathrm{s})\end{array}$ \\
\hline 4 & 0.7 & $3.85 \times 10^{-7}$ & 0.566 & 12,256 & 204 \\
8 & 1 & $7.85 \times 10^{-7}$ & 1.700 & 18,038 & 301 \\
\hline
\end{tabular}




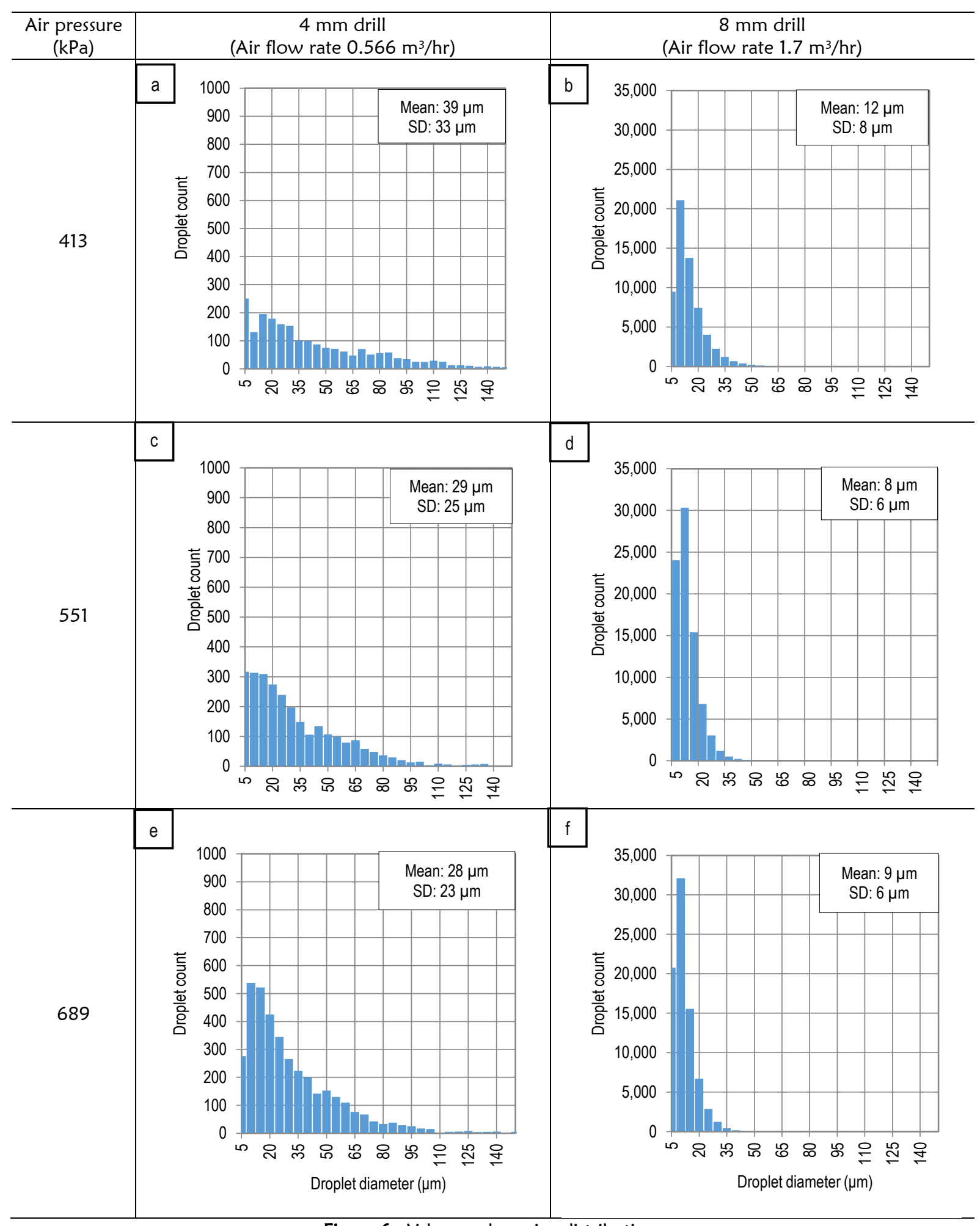

Figure 6. Airborne drop size distribution.

Mean and standard deviation of lubricant A's microdroplets at different air pressures. 


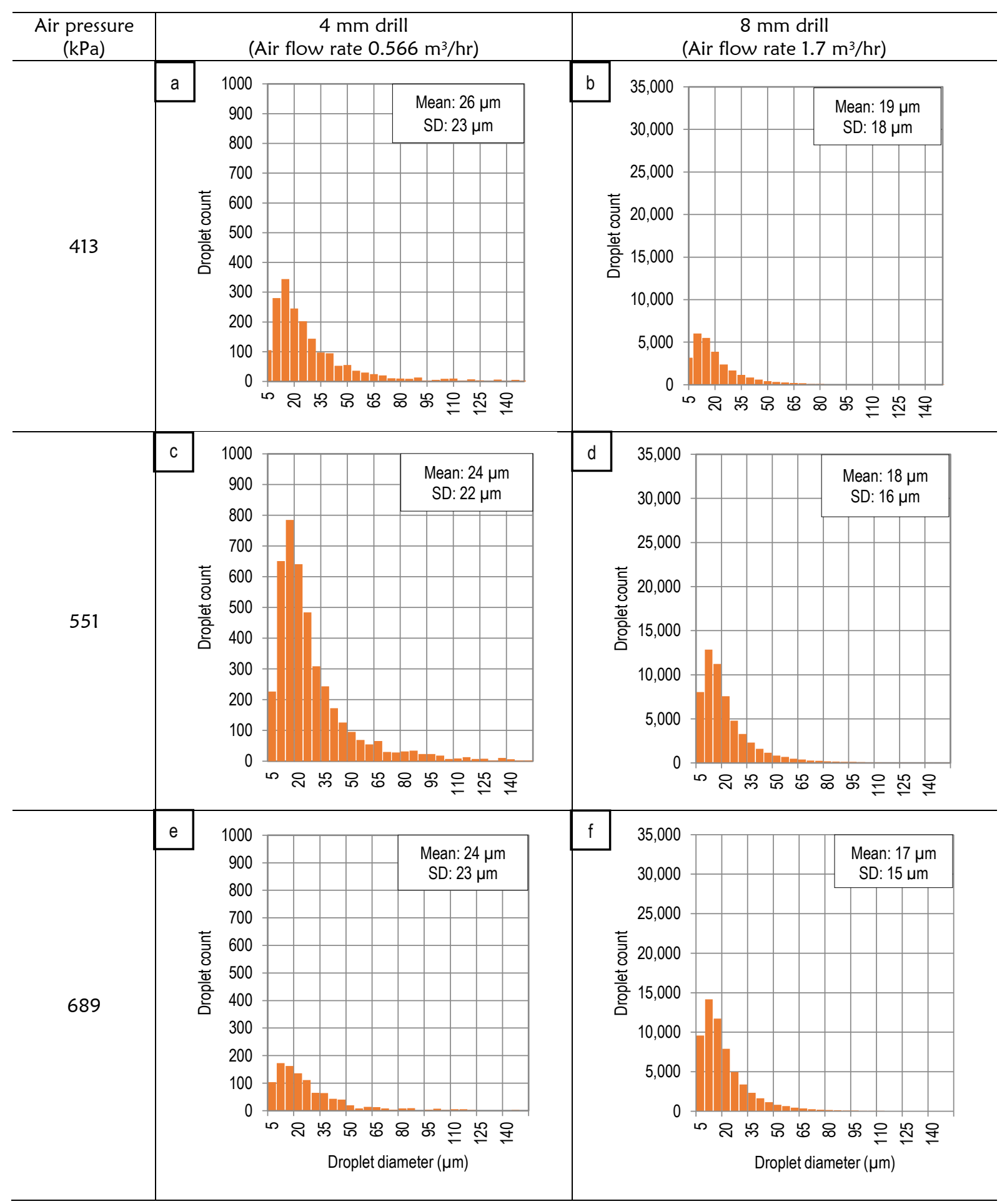

Figure 7. Airborne drop size distribution.

Mean and standard deviation of lubricant B's microdroplets at different air pressures. 
Figure 8 also shows that the numerical values of standard deviations are comparable to those of the mean airborne microdroplet diameters. A different approach was implemented for a better estimate. Instead of considering the average value of the whole data set, the microdroplets were divided statistically into different clusters depending on their sizes for further analysis.

Due to the large variation in airborne diameters, the K-means clustering method was used to divide all microdroplets into groups or clusters with different diameter ranges. For results of all cases, the "elbow method" was used to plot the within-cluster sum of square against number of possible number of clusters K (from 1 to 15) [29-31]. Figure 9 below shows typical elbow plots for airborne drop diameters of both oils with $4 \mathrm{~mm}$ drill operating at 551 $\mathrm{kPa}$ air pressure. There is a sudden drop in sum of squares at $K=3$ in every case; therefore, the total number of clusters is chosen to be three for effective comparison in all the cases and avoid overfitting of the data.

Figures 10a-d summarize the average airborne diameters resulted from the 4 and $8 \mathrm{~mm}$ drills at different pressures and oil types. For both the lubricants, the number of microdroplets collected from $8 \mathrm{~mm}$ drill was much more than those from the $4 \mathrm{~mm}$ drill due to the larger lubricant hole and higher air speed. The drop sizes can be divided into 3 clusters: clusters 1, 2, and 3 are for small, medium, and large drop size respectively.

- The variations within one cluster, shown as the error bars in Fig. 10, are much smaller than the drop size deviation in Fig. 8.

- Higher pressure reduces the average airborne drop size for all clusters, drill sizes, and lubricants. Notice the logscale on the vertical axis. This trend was confirmed with data from other published studies [15, 32].

- The larger drill size with larger channel hole generates smaller airborne microdroplets for lubricant A (Figs. 10ab). Similar results are seen for lubricant B (Figs. 10c-d).

- Lubricant A produces smaller microdroplets than lubricant B for all clusters and drill sizes when operating at the same air pressure.
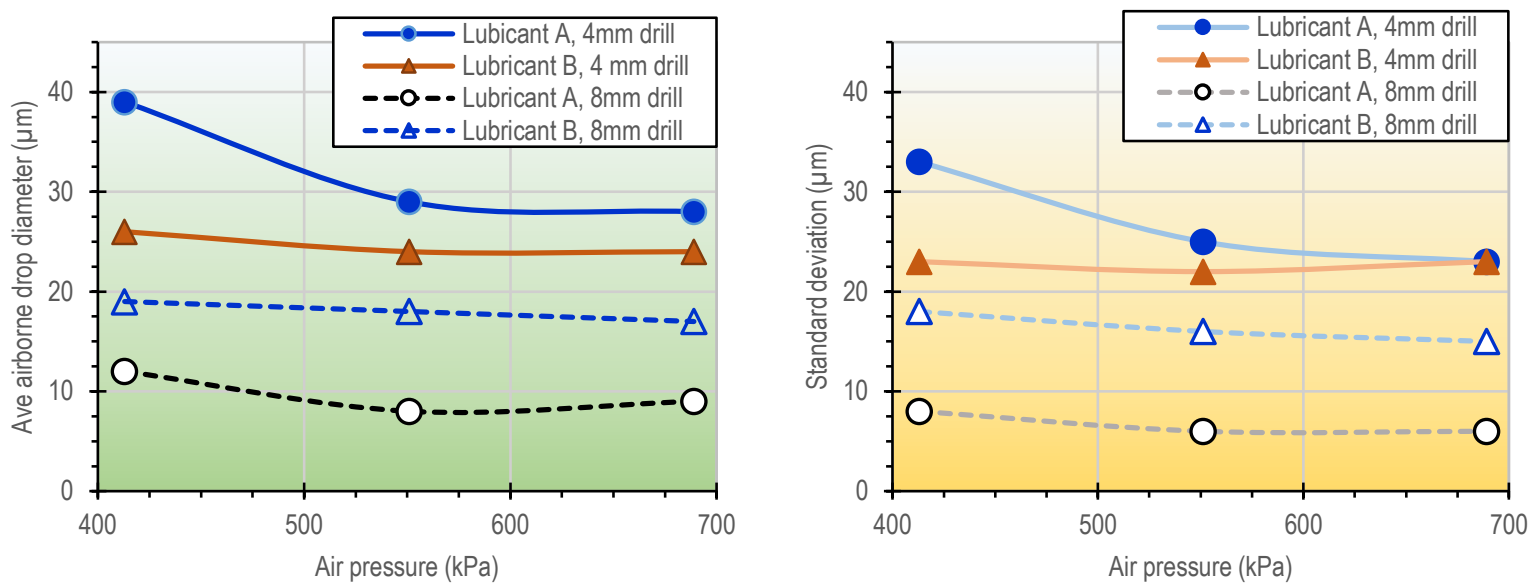

Figure 8. Summary of mean and standard deviation of airborne drop size distribution.

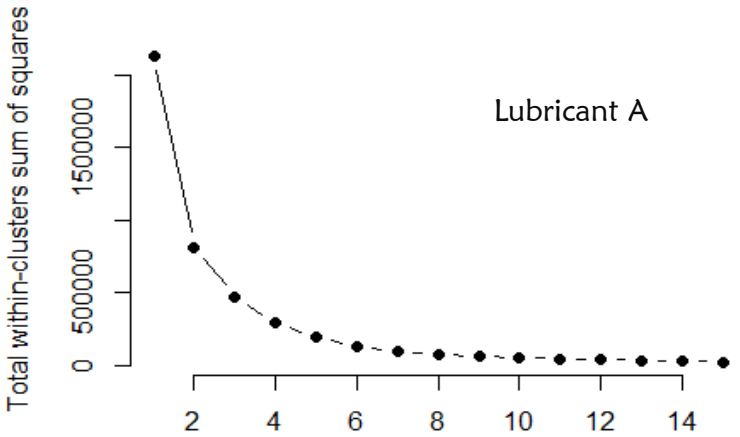

Number of clusters $\mathrm{K}$
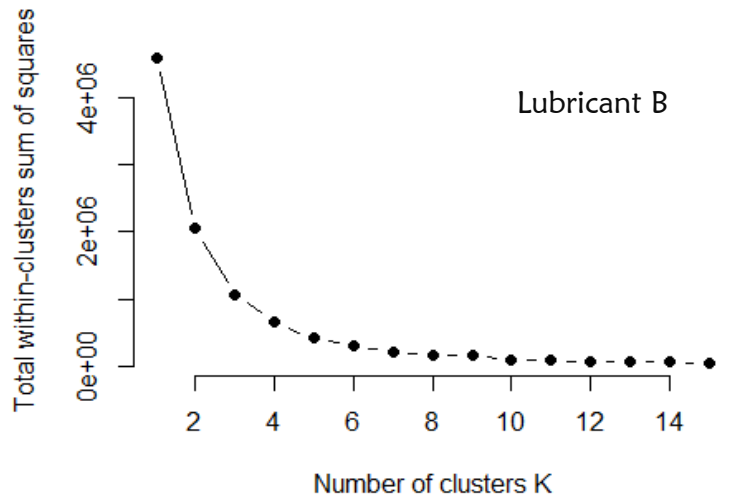

Figure 9. Elbow plots for airborne microdroplet diameters for both lubricants. $4 \mathrm{~mm}$ drill at $551 \mathrm{kPa}$ air pressure. 


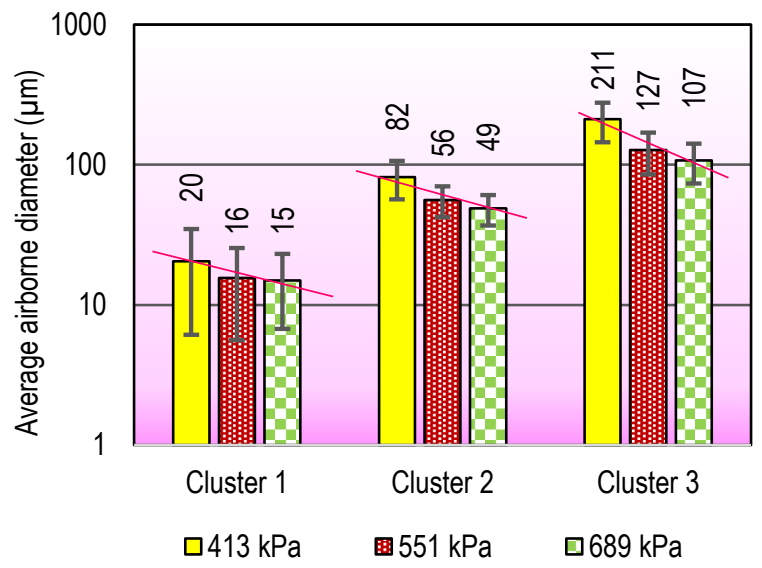

(a) Lubricant A, 4mm drill

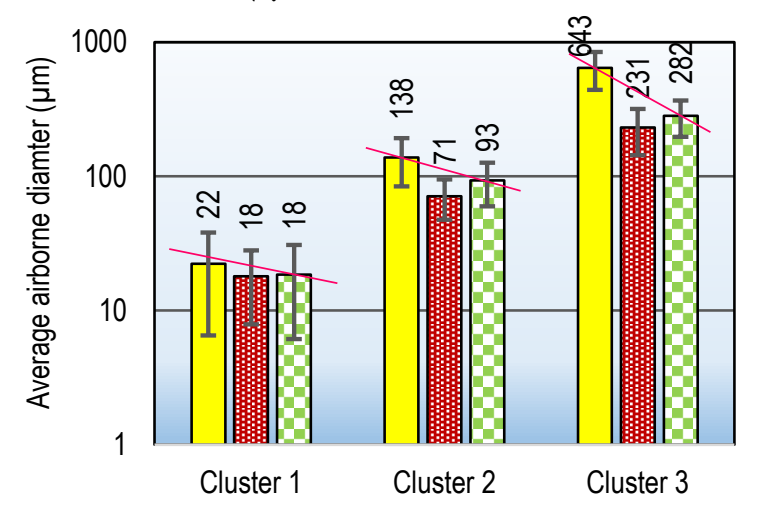

$\square 413 \mathrm{kPa} \quad$ 目 $551 \mathrm{kPa} \quad \square 689 \mathrm{kPa}$

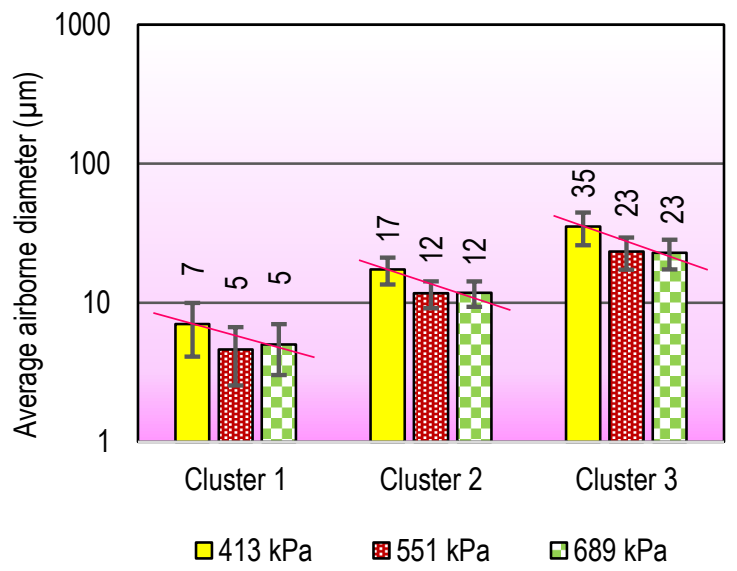

(b) Lubricant A, 8mm drill

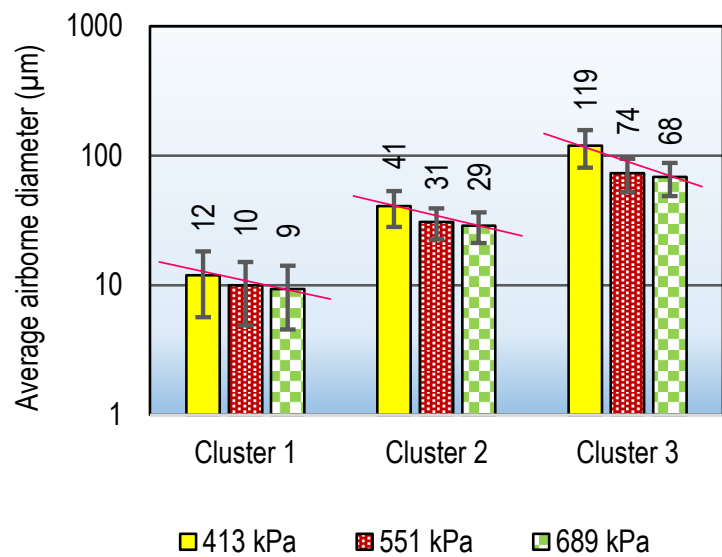

(d) Lubricant B, 8mm drill

Figure 10. Clusters showing effects of drill size and air pressure on airborne microdroplets.

\subsection{Microdroplet Formation and Flow}

High speed imaging technique was used to capture the microdroplet formation and flow of lubricants at the drill tip. The camera was not synchronized with the Unist pump; therefore, the time sequence of each picture was not corresponding with the pump frequency. Due to the relative low resolution of the video camera, microdroplets smaller than $50 \mu \mathrm{m}$ moving at high speed were not visible --although they were clearly visible with the Olympus microscope after depositing on a glass plate as mentioned above. The smaller $4 \mathrm{~mm}$ drill with $0.7 \mathrm{~mm}$ lubricant hole diameter was chosen in this part of the study since its smaller hole and spiral shape in space would be more difficult for the oil mist to flow. Other factors that affected the flow would include hole shape, air pressure [16-18], oil viscosity, surface tensions of oil and drill materials. The aerosol flowing out of a stationary drill was shown to approximately equivalent to that from a rotating drill since the lateral speed due to spindle rotation was very small compared to the exiting air speed at the drill tip [16].

Figure 11 captures the microdroplet formation of lubricants $A$ and $B$ at the drill tip. The two columns show the $265^{\text {th }}$ and $669^{\text {th }}$ image frames for lubricant $A$ and $B$ respectively.

- It took the lubricant $B$ a longer response time to flow out of small coolant hole due to its higher viscosity (28 $\left.\mathrm{mm}^{2} / \mathrm{s}\right)$ compared to that of lubricant $A\left(14.5 \mathrm{~mm}^{2} / \mathrm{s}\right)$. Visible microdroplet formation is seen after $6 \mathrm{~ms}$ for lubricant $A$, but not until $16 \mathrm{~ms}$ for lubricant $B$.

- At the low pressure of $413 \mathrm{kPa}$, visible large airborne drops of lubricant $A$ are seen (Fig. 11a) but a large amount of lubricant $B$ is still adhered to the drill tip (Fig. 11b). High viscosity and low surface tension promote the adhesion of lubricant $B$ to the drill tip.

- At the medium pressure of $551 \mathrm{kPa}$, both oil pools at the drill tip are broken up to form long string-like oil threads (Figs 11c-d).

- When further increasing the air pressure to $689 \mathrm{kPa}$, the oil thread is still visible for lubricant B (Fig. 11f), but such oil thread is completely disintegrated into airborne microdroplets for lubricant A (Fig. 11e). 


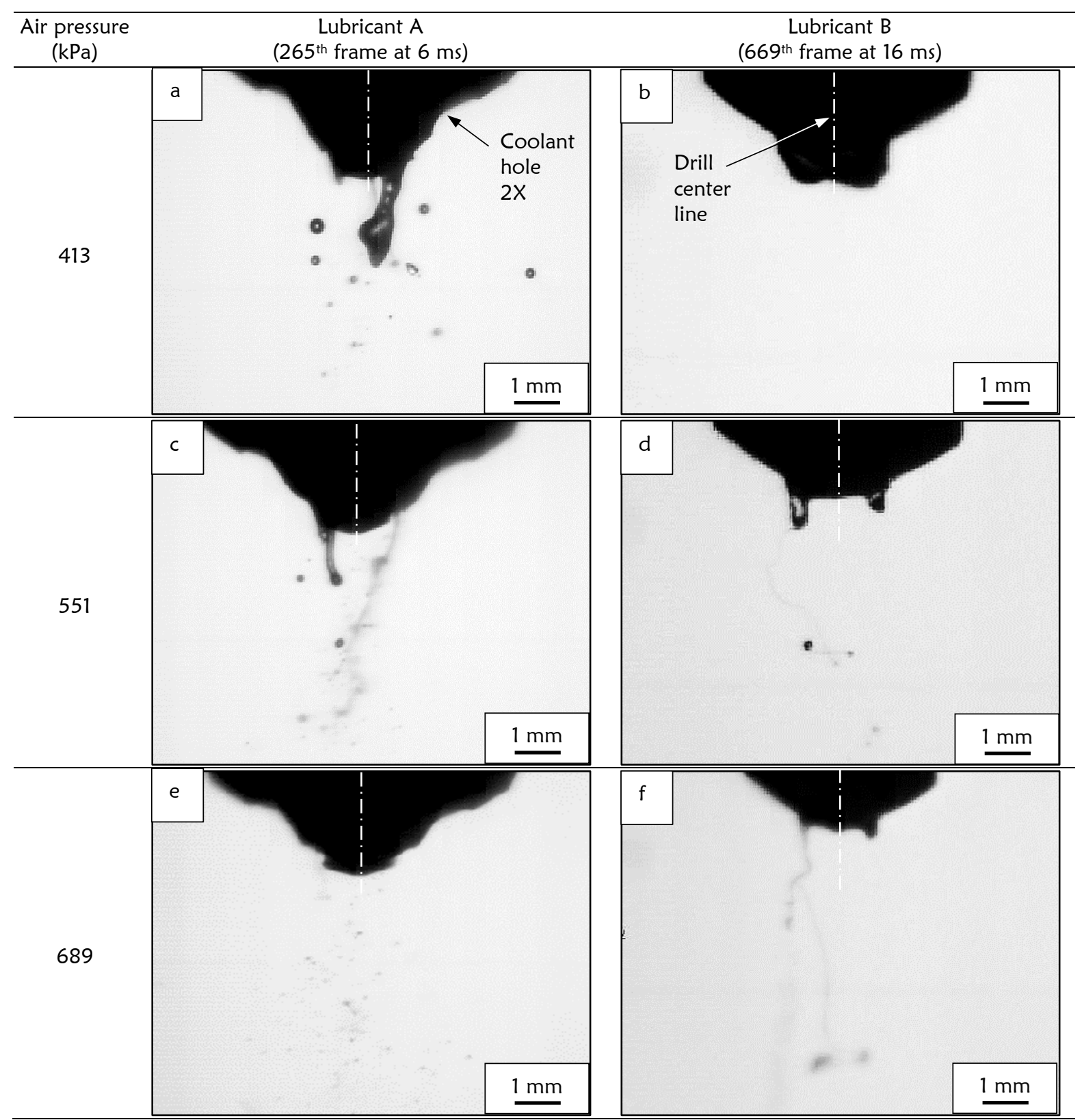

Figure 11. Microdroplet formations at the $4 \mathrm{~mm}$ drill tip due to different air pressures.

In this dual channel MQL system, the aerosol was atomized in a small chamber just before entering the two coolant holes of the twist drill. Upon entering the small channels, oil microdroplets must flow and impact the coolant channel wall since the channel axis was spirally downstream of the aerosol flow. It was postulated that most microdroplets would combine and become liquid flowing slowly downstream on the channel wall (Fig. 11b). The motion of oil liquid in the channel was affected by competing factors among viscosity of the oil, wetting of the wall surface, surface finish of the wall, gravity, air pressure, and low air speed at the wall. When flowing out of the channel and accumulated at the channel exit near the drill tip, the oil was atomized again and formed new microdroplets into the air stream (Fig. 11d); the oil atomization was cyclically activated since oil was pumped at the setup frequency of the Unist system. In flight coalescence of microdroplets was also evidenced due to overlapping jet streams from two channels in front of a drill tip (Fig. 11c). Complete atomization is achieved at air pressure of at least $689 \mathrm{kPa}$ for low viscous oil such as the lubricant A (Fig. 11e).

Two microdroplet formation mechanisms are evident in the high-speed video. Recall that the Unist system operated at 40 strokes/min $(0.67 \mathrm{~Hz})$ in this study. During the inactive stroke, the system sucked in $0.016 \mathrm{~mL}$ of lubricant from the reservoir and then pumped this volume to the air-jet stream during its active stroke. Under a steady air flow, microdroplets are formed continuously, but additional microdroplets are formed during the active pump stroke. 
- During the inactive stroke some oil microdroplets deposit on the inner channel wall, form a stream of lubricant, flow downstream with additional gravity effect, and then collect as a lubricant pool at the drill tip. When the cumulative volume of lubricant is sufficient large, the air stream then breaks the lubricant pool into oil strings and large microdroplets (Fig. 12a).

- During the active stroke, a fresh volume of lubricant is pumped into the air-jet stream and atomized inside the aerosol reservoir positioned above the drill shank (label " $g$ " in Fig. 1a). The newly atomized aerosol then flows into both lubricant channels and exits out of the holes near the drill tip (Figs. 12b, d). Cyclic bursts of oil microdroplets can be seen in synchronicity with the pumping frequency. Coalescence of airborne microdroplets are expected from the large microdroplets that come from the pool at drip tip and the smaller microdroplets that exit from the lubricant channels. Notice that the fine aerosol streams are visible at each hole exits near the drill centreline. Perhaps there are finer microdroplets at the exit holes away from the centreline, but such micronlevel airborne microdroplets are not captured due to insufficient resolution of the Photron camera in this study.

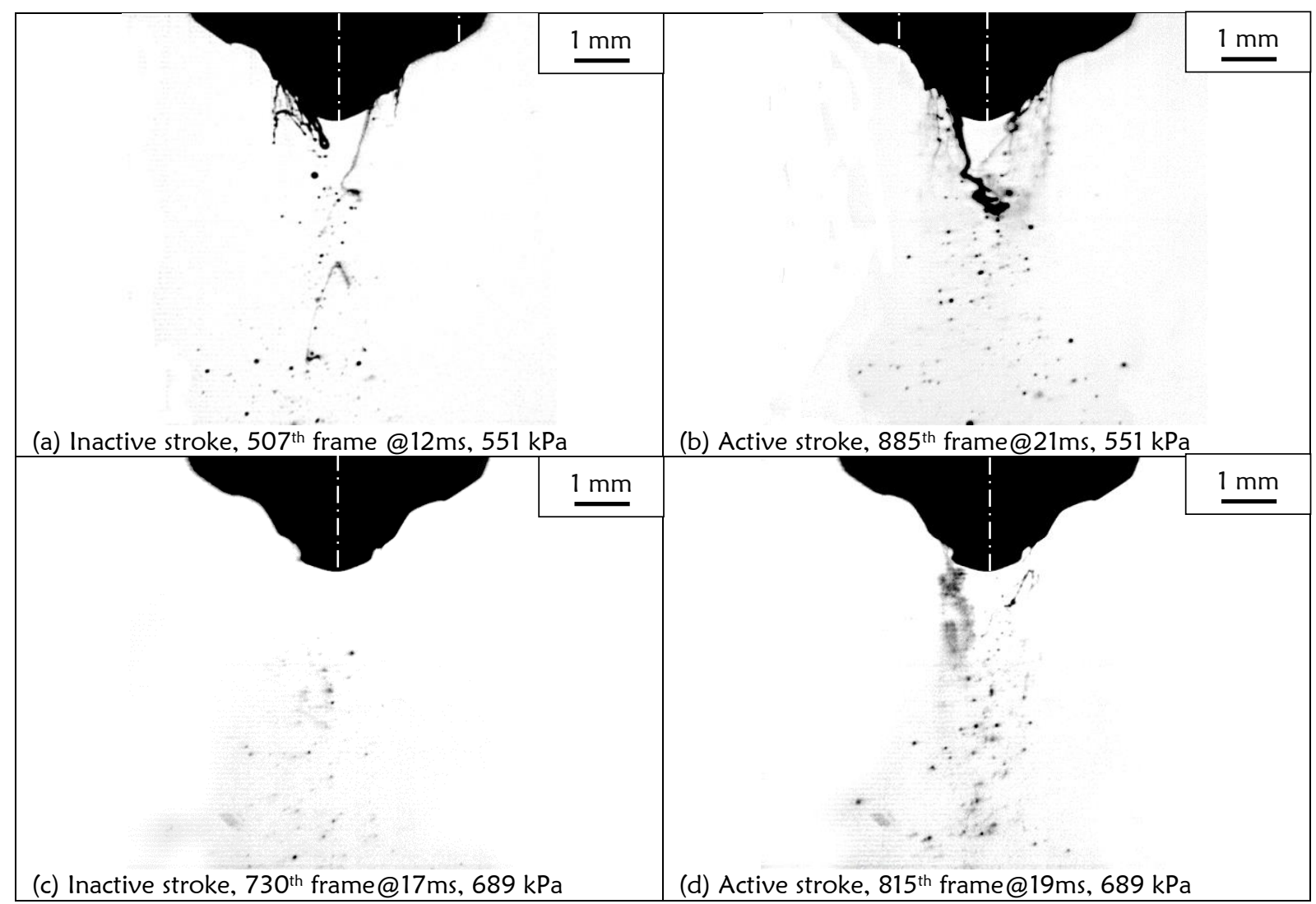

Figure 12. Effect of pump frequency on microdroplet formation. Lubricant A, $4 \mathrm{~mm}$ drill, pump frequency $0.67 \mathrm{~Hz}$ (40 strokes/min).

\subsection{Drilled Hole Quality}

Define the "hole oversize" and "cylindricity" as:

Hole oversize $=$ (measured hole diameter) - (measured drill size)

The hole oversize is due to one or combining effects of:

$$
\text { Cylindricity }=\text { radial deviation of all circles on a right cylinder }
$$

- vibration of tool and/or workpiece

- runout of machine tool spindle

- defective drill

- drill with poor cylindricity

- travel error of the machine tool axis

- thermal distortion during machining

- redistribution of residual stress

- tool degradation during drilling

- material defects

- Etc... 

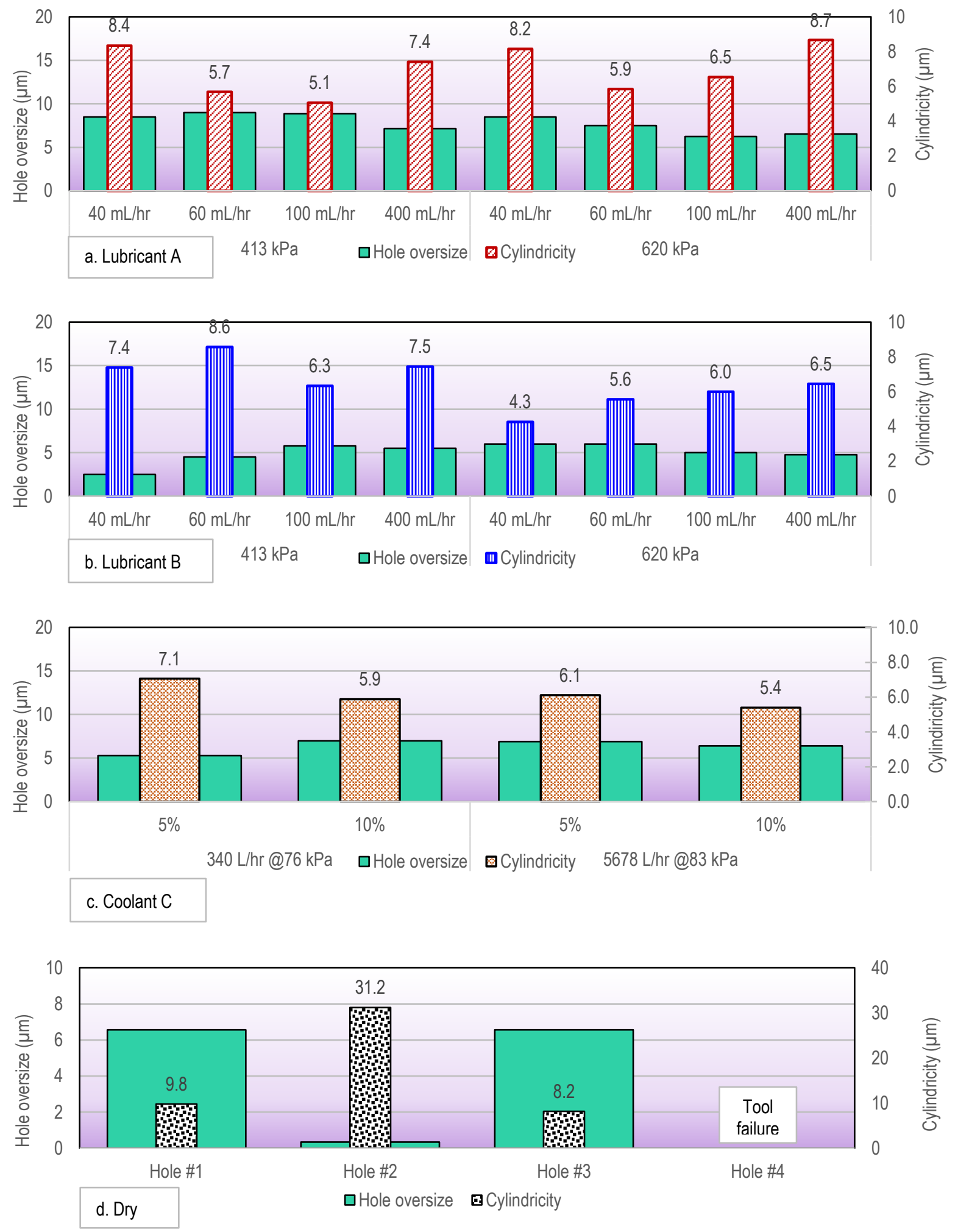

It is assumed that:

Figure 13. Average hole oversize and cylindricity of drilled holes.

- thermal effects are insignificant when copious coolant is used

- insignificant carbide drill wear when machining the soft cast aluminium alloy

- there is no performance difference among three different CNC drilling machines

- cast defects, such as porosity, do not affect the drilling process or measuring results

- low residual stress in the cast plate 
The three different machines were used to avoid changing cutting fluids and possible cross contamination. Only the last test was performed without coolant. The drilling parameters for production mode $(250 \mathrm{~m} / \mathrm{min}, 0.20 \mathrm{~mm} / \mathrm{flute})$ were referenced from the Machinery Handbook for carbide tool and A380 cast aluminium. No pecking was programmed to simulate a fast production environment.

Figure 13 plots the hole deviation and hole cylindricity for all test data. Each data point is the average of measurements from five holes that were drilled at the same conditions and two replicates (total of 10 holes). Drilling without coolant (dry condition) generated significant built-up edge and friction between the drill and workpiece. After drilling 3 holes on the plate, the drill was twisted off during drilling the $4^{\text {th }}$ hole. Table 7 and Figure 14 summarize the information from Figure 13. The data suggest:

- There is no significant impact of oil quantity to the drilled hole quality. It would be more cost effective and environmentally friendly to use either lubricant $A$ or $B$ at $40 \mathrm{~mL} / \mathrm{hr}$ instead of $400 \mathrm{~mL} / \mathrm{hr}$. Similarly, the concentration of lubricant $C$ could be $5 \%$ instead of $10 \%$.

- Drilling with lubricant B as MQL oil provided the least hole oversize. The average of hole oversize for drilling all 80 holes was $5.0 \mu \mathrm{m}$.

- Drilling with lubricant $C$ as flood coolant generated the best hole shape with $6.1 \mu \mathrm{m}$ cylindricity and lowest standard deviation. Perhaps the least amount of heat that generated during drilling in this water-soluble flood coolant would minimize thermal distortion in the workpiece [3, 33].

Table 7. Summary of hole oversize and cylindricity

\begin{tabular}{lcccc}
\hline \multirow{2}{*}{ Lubricant } & \multicolumn{2}{c}{ Hole oversize $(\mu \mathrm{m})$} & \multicolumn{2}{c}{ Cylindricity $(\mu \mathrm{m})$} \\
Lubricant A & Average & Standard deviation & Average & Standard deviation \\
Lubricant B & 7.8 & 1.6 & 7.0 & 1.8 \\
Coolant C & 5.0 & 1.4 & 6.5 & 2.1 \\
Dry & 6.4 & 1.5 & 6.1 & 1.0 \\
\hline
\end{tabular}
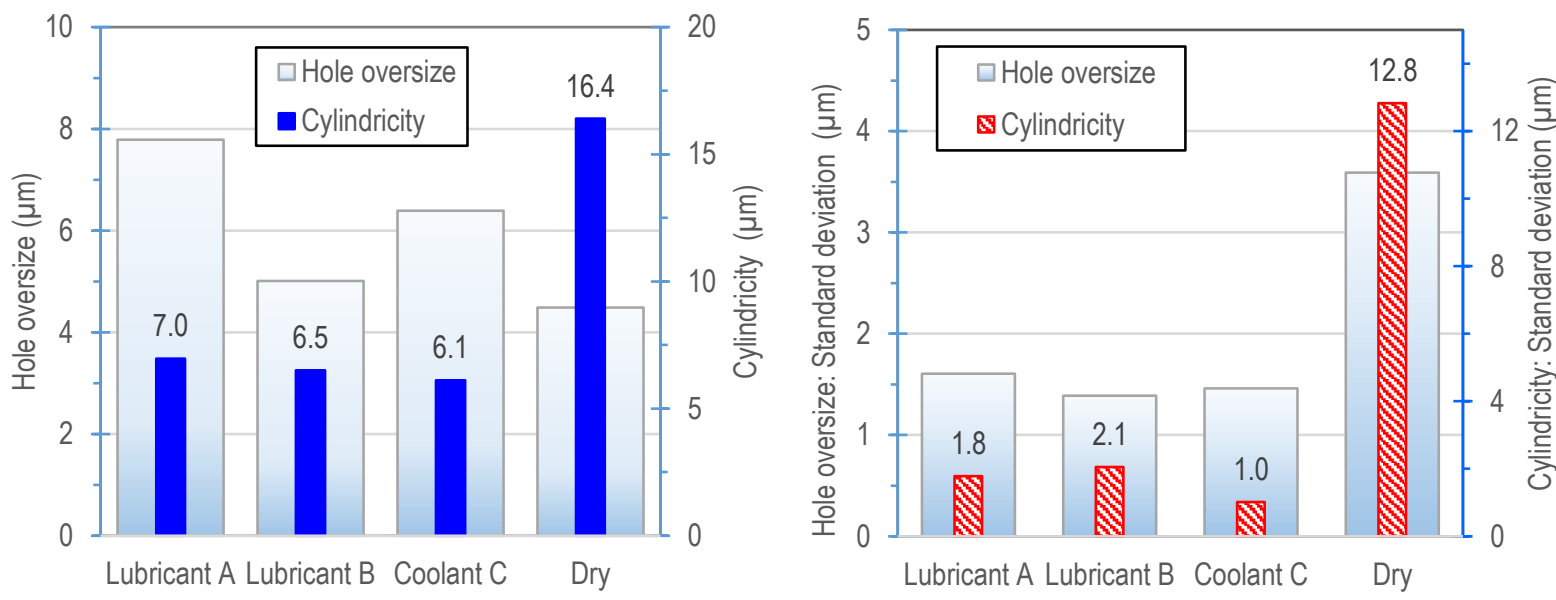

Figure 14. Summary of hole oversize and cylindricity

Cutting flute profiles of a drill were scanned after drilling in both MQL lubricants. The tool used after flood cooling and dry drilling was not scanned since it was broken and embedded into the partially drilled hole. Microscopic examination shows wear on one of the cutting flutes after drilling with lubricant A (Fig. 15a). Abrasive wear of the drill on one flute (i) might be caused by tool defect rather than normal tool wear in drilling since the other flute remains sharp after all tests, (ii) may cause imbalance and affect the hole oversize and cylindricity as measured and summarized in Table 7. Figure 15b shows significant built-up edges (BUE) near the drill centre (chisel edge) after drilling with lubricant $\mathrm{B}$; it is common to have BUE on cutting tools when machining a soft material such as aluminium at low cutting speed - as seen at the drill centre [34-35]. However, such BUE is minimum on the drill lubricated with lubricant A. Lack of BUE on tool with lubricant A could be due to the effective lubrication of this oil; recalled that lubricant $A$ formed smaller contact angle on aluminium compared to lubricant $B$ which implied better wetting and lubrication. Surface finish would be affected by BUEs since they smear and deposit on drilled surface. It is true that tool coating could minimize BUE and improve the part quality [13,36], but it would be cost prohibitive to recycle coated drills with through-tool MQL channels. 

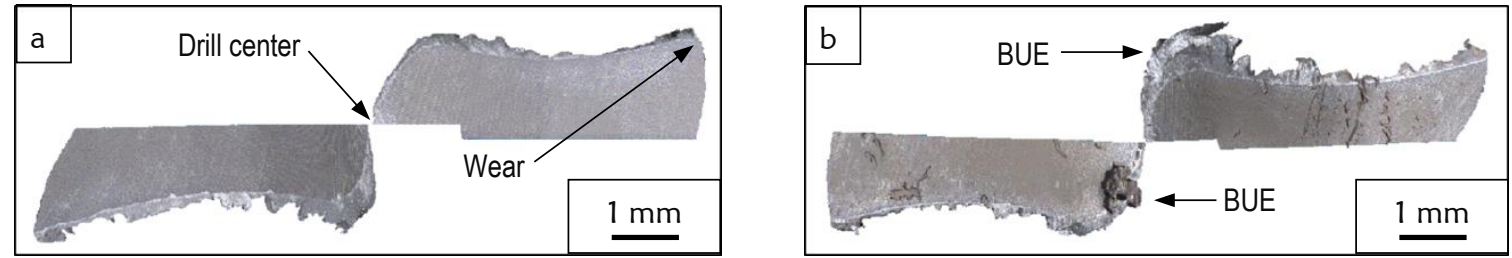

Figure 15. Drill edge profiles after drilling 80 holes. (a) Abrasive wear on one flute after drilling with lubricant $A$ and (b) Built-up edges (BUE) when drilling with lubricant B.

Published data on external MQL have shown that smaller airborne drop size improved machinability [15]. In internal MQL drilling the aerosol that exiting out of the coolant channels would flow against the drill rotation direction on the second flank face of the drill, and then fill the 3-dimensional space confined by a flute rake face and its spiral surface (Fig 1b). Smaller microdroplets with high wetting capability can (i) penetrate the interface between the chips and drill cutting edges, and (ii) cool the chip and tool effectively. Thermal conductivity of an oil affects the cooling rate and reduces tool wear. Viscosity affects the capillary motion; a less viscous lubricant penetrates the tool/chip interface and lubricates both cutting edges of the drill and reduces BUE formation. The German DIN standard EN ISO 2592 [20] recommends the minimum viscosity of $10 \mathrm{~mm} / \mathrm{s}$ for MQL oil. This limit is met for both oils in this study, however, the lubricant A's viscosity $\left(14.5 \mathrm{~mm}^{2} / \mathrm{s}\right)$ is about half of that for lubricant B $\left(28 \mathrm{~mm}^{2} / \mathrm{s}\right)$. Using a low viscosity oil may shorten the drilling cycle time since the less viscous oil reaches MQL aerosol state faster (shorter response time) for each oil pumping cycle (Fig. 11 a-d) and less time to flow from oil reservoir and along a long narrow tube to the atomization chamber.

Further regression and ANOVA analysis of the hole oversize and cylindricity was performed. The models for hole oversize and cylindricity for each lubricants are shown below.

For lubricant A:

For lubricant B:

$$
\begin{gathered}
H_{o}=10.90-4.81 \times 10^{-3} A_{p}-3.85 \times 10^{-3} O_{q} \\
C_{y}=4.99+2.86 \times 10^{-3} A_{p}+3.57 \times 10^{-3} O_{q}
\end{gathered}
$$

$$
\begin{aligned}
& H_{o}=0.75+6.73 \times 10^{-3} A_{p}+2.13 \times 10^{-3} O_{q} \\
& C_{y}=11.01-9.33 \times 10^{-3} A_{p}+2.31 \times 10^{-3} O_{q}
\end{aligned}
$$

For lubricant $C$ (flood coolant):

$$
\begin{gathered}
H_{o}=5.20+9.8 \times 10^{-5} F_{f}+0.119 C_{c} \\
C_{y}=7.94-1.35 \times 10^{-4} F_{f}-0.189 C_{c}
\end{gathered}
$$

Where,

$H_{0}$ : hole oversize $(\mu \mathrm{m})$

$C_{y}:$ cylindricity $(\mu \mathrm{m})$

$A_{p}$ : air pressure $(\mathrm{kPa})$

$O_{q}$ : oil quantity $(\mathrm{mL} / \mathrm{hr})$

$F_{f}$ : flood coolant flow (L/hr)

$C_{c}$ : coolant concentration in water (\%).

The above models, however, were not conclusive since $\mathrm{R}^{2}<10 \%$ and P-value $>0.05$. Perhaps the data were affected by testing that performed on different machines with different rigidity, accuracy, repeatability, and spindle runout. Any variation of machine tool conditions could invalid the above assumptions and affect measurement results of the drilled holes. It is also recommended that at least 3-level experiment with pressure values should be performed for drilling.

\section{CONCLUSIONS AND RECOMMENDATIONS}

This study characterized two commercially available lubricants $A$ and $B$ for internal minimum quantity lubrication (MQL), and then performed through-tool MQL drilling on $A 380$ cast aluminium at fast production rate. Drilling using flood water-soluble coolant $C$ was also experimented for comparison. The research showed:

1) Contact angles of lubricant $A$ on glass and aluminium were at least $10^{\circ}$ less than those from lubricant $B$. The low contact angle promoted wetting for effective lubricating and cooling.

2) Statistical analysis of air borne microdroplets was completed. Clustering method divided the airborne microdroplets into three clusters for comparison. The drop sizes were reduced due to higher air pressure and larger coolant channel. Lubricant A microdroplets were smaller than lubricant B's for all clusters, drill sizes at same operating conditions.

3) High speed video camera was used to observe the microdroplet formation and MQL flowing out of a drill channel. Lubricant A, with lower viscosity, flowed easily and was atomized at lower air pressure than lubricant B. In flight microdroplet coalescence was observed due to overlapping regions of the MQL jet streams. High oil pumping frequency produced consistent quality of aerosol and should be used in high speed machining or high production mode. 
4) Drilled hole quality was measured by cylindricity and deviation of hole diameter. Drilling in MQL with lubricant $B$ produced the most consistent hole size while drilling in flood coolant $C$ produced the holes with best cylindricity. Drilling with lubricant A reduced built-up-edge on the drill cutting edges.

Future studies should:

a) Minimize machining variation by drilling with one $\mathrm{CNC}$ machine to truly compare the effect of different $\mathrm{MQL}$ lubricants assuming a rigid setup and no cross contamination of lubricants.

b) Consider surface finish as part of drilled hole quality since built-up edges on a tool could smear and degrade a machined surface.

c) Assess the effectiveness of internal MQL by deep drilling engineering alloys with poor machinability such as tool steel, Inconel or Cobalt-chrome.

\section{ACKNOWLEDCEMENT}

The authors thank Ford, Unist, and Mitutoyo for their kind supports. This material is based upon work supported by the National Science Foundation under the GOALI Grant No. 1760985.

\section{REFERENCES}

1. Dasch, J. M., \& Kurgin, S. K. (2010). A characterisation of mist generated from minimum quantity lubrication (MQL) compared to wet machining. Machining and Machinability of Materials, 7(1-2), 82-95. https://doi.org/10.1504/IJMMM.2010.029847

2. Aized, T., \& Amjad, M. (2013). Quality improvement of deep-hole drilling process of AISI D2. Advanced Manufacturing Technology, 69(9-12), 2493-2503. https://doi.org/10.1007/s00170-013-5178-4

3. Bono, M., \& Ni, J. (2001). The effects of thermal distortions on the diameter and cylindricity of dry drilled holes. Machine Tools and Manufacture, 41(15), 2261-2270. https://doi.org/10.1016/S0890-6955(01)00047-5

4. Kaplan, Y., Motorcu, A. R., Nalbant, M., \& Okay, S. (2015). The effects of process parameters on acceleration amplitude in the drilling of cold work tool steels. Advanced Manufacturing Technology, 80(5-8), 1387-1401. https://doi.org/10.1007/s00170-015-7097-z

5. Khan, S. A., Nazir, A., Mughal, M. P., Saleem, M. Q., Hussain, A., \& Ghulam, Z. (2017). Deep hole drilling of AISI 1045 via high-speed steel twist drills: evaluation of tool wear and hole quality. International Advanced Manufacturing Technology, 93(1-4), 1115-1125. https://doi.org/10.1007/s00170-017-0587-4

6. Li, R., Hegde, P., \& Shih, A. J. (2007). High-throughput drilling of titanium alloys. Machine Tools and Manufacture, 47(1), 63-74. https://doi.org/10.1016/j.ijmachtools.2006.02.012

7. Rahim, E. A., \& Sharif, S. (2006). Investigation of tool life and surface integrity when drilling Ti-6A1-4V and Ti5A1-4V-Mo/Fe. JSME Series C: Mechanical Systems, Machine Elements and Manufacturing, 49(2), 340-345. https://doi.org/10.1299/jsmec.49.340

8. Ramulu, M., Branson, T., \& Kim, D. (2001). A study on the drilling of composite and titanium stacks. Composite Structures, 54(1), 67-77. https://doi.org/10.1016/S0263-8223(01)00071-X

9. Zhang, P. F., Churi, N. J., Pei, Z. J., \& Treadwell, C. (2008). Mechanical drilling processes for titanium alloys: A literature review. In Machining Science and Technology (Vol. 12, Issue 4, pp. 417-444). https://doi.org/10.1080/10910340802519379

10. Sivalingam, V., Zan, Z., Sun, J., Selvam, B., Gupta, M. K., Jamil, M., \& Mia, M. (2020). Wear behaviour of whisker-reinforced ceramic tools in the turning of Inconel 718 assisted by an atomized spray of solid lubricants. Tribology International, 106235. https://doi.org/10.1016/j.triboint.2020.106235

11. Minh Duc, T., The Long, T., \& Van Thanh, D. (2020). Evaluation of minimum quantity lubrication and minimum quantity cooling lubrication performance in hard drilling of Hardox 500 steel using $\mathrm{Al}_{2} \mathrm{O}_{3}$ nanofluid. Advances in Mechanical Engineering, 12(2), 1-12. https://doi.org/10.1177/1687814019888404

12. Okafor, A. C., \& Nwoguh, T. O. (2020). A study of viscosity and thermal conductivity of vegetable oils as base cutting fluids for minimum quantity lubrication machining of difficult-to-cut metals. Advanced Manufacturing Technology, 106(3-4), 1121-1131. https://doi.org/10.1007/s00170-019-04611-3

13. Braga, D. U., Diniz, A. E., Miranda, G. W. A., \& Coppini, N. L. (2002). Using a minimum quantity of lubricant (MQL) and a diamond coated tool in the drilling of aluminum-silicon alloys. Materials Processing Technology, 122(1), 127-138. https://doi.org/10.1016/S0924-0136(01)01249-3.

14. Stephenson, D. A., and Agapiou, J. S. (2016). Metal Cutting Theory and Practice. 3rd Ed., Chapter 15, Boca Raton, FL: CRC Press.

15. Khan, W. A., Hoang, N. M., Tai, B., \& Hung, W. N. P. (2018). Through-tool minimum quantity lubrication and effect on machinability. Manufacturing Processes, 34 34(March), 757. https://doi.org/10.1016/j.jmapro.2018.03.047

16. Kao, Y. T., Takabi, B., Hu, M., \& Tai, B. L. (2017). Coolant channel and flow characteristics of MQL drill bits: Experimental and numerical analyses. ASME 2017 12th International Manufacturing Science and Engineering 
Conference, MSEC 2017 Collocated with the JSME/ASME 2017 6th International Conference on Materials and Processing, 2, 1-7. https://doi.org/10.1115/MSEC2017-3060

17. Raval, J. K., Kao, Y.-T., \& Tai, B. L. (2019). Characterizing Mist Distribution in Through Tool Minimum Quantity Lubrication (MQL) Drills. Manufacturing Science and Engineering, 1-16. https://doi.org/10.1115/1.4045799

18. Raval J.K., Hung W.N.P., and Tai B.L, (2019). Multiphase flow distribution in MQL drilling using optical intensity distribution-based approach, MSEC2019-2926, ASME 14 ${ }^{\text {th }}$.

19. Hughey, E., and Stephenson, D. (2019). Oil delivery balancing and priming for multi-diameter minimum quantity lubrication tooling assemblies. 47th SME North American Manufacturing Research Conference, Procedia Manufacturing, 34: 343-348.

20. Fachausschuss Information Sheet No. 006. (2005). Low-emitting metal working with minimum quantity lubrication.

21. Li, Q., Lerma, I., Alvarado, J., Edinbarough, I., \& Hung, W. N. P. (2015). Characterization of micromist for effective machining. ASME International Mechanical Engineering Congress and Exposition, Proceedings (IMECE), 2A-2015. https://doi.org/10.1115/IMECE2015-53632

22. Tai, B. L., Dasch, J. M., \& Shih, A. J. (2011). Evaluation and comparison of lubricant properties in minimum quantity lubrication machining. Machining Science and Technology, 15(4), 376-391. https://doi.org/10.1080/10910344.2011.620910

23. Dynacast. (n.d.). https://www.dynacast.com/en/knowledge-center/material-information/die-castmetals/aluminum-die-casting-metals/aluminum-alloy-a380-

24. Star SU LLC. (n.d.). https://www.star-su.com/cutting-tools/gundrills/solid-carbide-twist-drills/

25. Sharon-Cutwell Co. Inc. (n.d.). https://cutwell.com/

26. Kajaria S., (2009). Modeling of tool life and micro-mist flow for effective micro-machining of 316L stainless steel. Thesis, Texas A\&M University, pp 115-119.

27. Stephenson, D., Hughey, E., and Hasham, A.A. (2019). Air flow and chip removal in minimum quantity lubrication drilling. 47th SME North American Manufacturing Research Conference, Procedia Manufacturing, 34: 335-342.

28. Liu, Z. Q., Cai, X. J., Chen, M., \& An, Q. L. (2012). Selection of minimum quantity lubrication (MQL) parameters in milling of Ti-6Al-4V. Advanced Materials Research, 426, 139-142. https://doi.org/10.4028/www.scientific.net/AMR.426.139

29. James, G., Witten, D., Hastie, T., \& Tibshirani, R. (2017). An introduction to statistical learning: With applications in R. Chapter 10, New York: Springer. https://doi.org/10.1007/978-1-4614-7138-7

30. Marutho, D., Hendra Handaka, S., Wijaya, E., \& Muljono. (2018). The Determination of Cluster Number at kMean Using Elbow Method and Purity Evaluation on Headline News. Proceedings - 2018 International Seminar on Application for Technology of Information and Communication: Creative Technology for Human Life, ISemantic 2018, 533-538. https://doi.org/10.1109/ISEMANTIC.2018.8549751

31. K-means Cluster Analysis, https://uc-r.github.io/kmeans_clustering\#elbow, Access 2 June 2020.

32. Park, K.H., Olortegui-Yume, J., Yoon, M.C., and Kwon, P. (2010). A study on droplets and their distribution for minimum quantity lubrication (MQL), Machine Tools \& Manufacture, 50:824-833.

33. Tai, B. L., Jessop, A. J., Stephenson, D. A., \& Shih, A. J. (2012). Workpiece thermal distortion in minimum quantity lubrication deep hole drilling-finite element modelling and experimental validation. Manufacturing Science and Engineering, Transactions of the ASME, 134(1). https://doi.org/10.1115/1.4005432.

34. Wang, Z., Kovvuri, V., Araujo, A., Bacci, M., Hung, W. N. P., \& Bukkapatnam, S. T. S. (2016). Built-up-edge effects on surface deterioration in micromilling processes. Manufacturing Processes, 24, 321-327. https://doi.org/10.1016/j.jmapro.2016.03.016.

35. Kovvuri, V., Wang, Z., Araujo, A., Da Silva, M. B., Bukkapatnam, S., \& Hung, W. N. P. (2015). Built-Up-Edge Formation in Micromilling. https://asmedigitalcollection.asme.org/lMECE/proceedingspdf/IMECE2015/57359/N02AT02A057/2492078/v02at02a057-imece2015-53390.pdf

36. Barnes, S., \& Pashby, I. R. (2000). Through-tool coolant drilling of aluminum/SiC metal matrix composite. Engineering Materials and Technology, Transactions of the ASME, 122(4), 384-388. https://doi.org/10.1115/1.1288925. 